Guoliang Wang · Qingling Zhang Xinggang Yan

Analysis

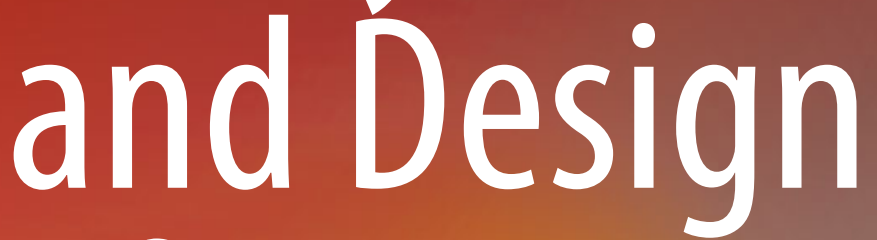

of Singular

Markovian

Jump Systems

Springer 
Analysis and Design of Singular Markovian Jump Systems 
Guoliang Wang · Qingling Zhang Xinggang Yan

\section{Analysis and Design of Singular Markovian Jump Systems}

算 Springer 
Guoliang Wang

Liaoning Shihua University

Fushun

China

Qingling Zhang

Institute of Systems Science

State Key Laboratory of Synthetical

Automation for Process Industries

Northeastern University

Shenyang

China
Xinggang Yan

School of Engineering and Digital Arts

The University of Kent

Kent, CT

UK

ISBN 978-3-319-08722-1

ISBN 978-3-319-08723-8 (eBook)

DOI $10.1007 / 978-3-319-08723-8$

Library of Congress Control Number: 2014943403

Springer Cham Heidelberg New York Dordrecht London

(C) Springer International Publishing Switzerland 2015

This work is subject to copyright. All rights are reserved by the Publisher, whether the whole or part of the material is concerned, specifically the rights of translation, reprinting, reuse of illustrations, recitation, broadcasting, reproduction on microfilms or in any other physical way, and transmission or information storage and retrieval, electronic adaptation, computer software, or by similar or dissimilar methodology now known or hereafter developed. Exempted from this legal reservation are brief excerpts in connection with reviews or scholarly analysis or material supplied specifically for the purpose of being entered and executed on a computer system, for exclusive use by the purchaser of the work. Duplication of this publication or parts thereof is permitted only under the provisions of the Copyright Law of the Publisher's location, in its current version, and permission for use must always be obtained from Springer. Permissions for use may be obtained through RightsLink at the Copyright Clearance Center. Violations are liable to prosecution under the respective Copyright Law. The use of general descriptive names, registered names, trademarks, service marks, etc. in this publication does not imply, even in the absence of a specific statement, that such names are exempt from the relevant protective laws and regulations and therefore free for general use.

While the advice and information in this book are believed to be true and accurate at the date of publication, neither the authors nor the editors nor the publisher can accept any legal responsibility for any errors or omissions that may be made. The publisher makes no warranty, express or implied, with respect to the material contained herein.

Printed on acid-free paper

Springer is part of Springer Science+Business Media (www.springer.com) 


\section{Preface}

In recent decades, singular systems have been widely studied due to their extensive applications in various practical systems such as electrical systems, economics, chemical processes and mechanics, etc. Many fundamental results based on the state space representation have been successfully extended to singular systems. When the dynamics of practical systems modeled by singular systems change abruptly, singular Markovian jump systems (SMJSs) have the advantage of better representing such systems. These abrupt changes are usually caused by phenomena such as random failures or repairs, changes in subsystem interconnections, sudden environmental changes, and so on. Such a class of systems involves both timeevolving and event-driven mechanisms. The former is the state vector which is continuous in time, and the latter is the operation mode, which is driven by a Markov process and takes values in a finite space. It should be noted that many important results on analysis and design of singular systems have been achieved. However, SMJSs have not been thoroughly investigated and the results obtained for SMJSs are considerably limited.

The objective of this monograph is to present up-to-date research development and literature review on the analysis and design of SMJSs. Problems such as stability, stabilization, $H_{\infty}$ control, observer design, $H_{\infty}$ filtering, and adaptive control for SMJSs and applications of Markov process are to be studied using Lyapunov theory, linear matrix inequality (LMI), S-procedure and the stochastic Barbalat's Lemma, etc. This monograph contains valuable reference material to help the relevant researchers to explore SMJSs and carry on further research in the area. The contents are also suitable for a one-semester graduate course.

In this monograph, the stability problem of SMJSs with general transition rate matrices (TRMs) is first studied. Basic concepts and results on stability and robust stability are presented. Based on these fundamental results, the robust stabilization for SMJSs with uncertain TRMs via mode-dependent or mode-independent controller is introduced. Then, stabilization results via TRM design, noise control, proportional-derivative control, and partially mode-dependent control are obtained in terms of LMIs or LMIs with some equation constraints. Within an LMI framework, the problem of $H_{\infty}$ control in terms of mode-independent and 
mode-dependent control are considered, where a disordered $H_{\infty}$ controller is developed as well. Specifically, the mode-independent $H_{\infty}$ control problem is solved by several different methods. Sufficient LMI conditions on generally observer-based feedback stabilization are developed, where either of the designed controller or observer can be mode-dependent or mode-independent. Furthermore, based on an LMI approach, the problem of robust $H_{\infty}$ filtering is considered, while a method for partially mode-dependent filtering is proposed. In the case when bounds of TRMs of SMJSs are unknown or inaccessible, an adaptation law is developed to estimate the upper bounds of these parameters. LMI-based conditions for a class of adaptive state feedback controllers are presented such that not only the estimated error is bounded almost surely but also the corresponding closed-loop system are asymptotically stable almost surely. Finally, applications of the Markov process in singular systems with norm bounded uncertainties and time-varying delays are studied.

The work was partially supported by the National Natural Science Foundation of China under Grants 61104066, 61273008 and 61374043, the Royal Academy of Engineering of the United Kingdom with the Award 12/13RECI027, the China Postdoctoral Science Foundation funded project under Grant 2012M521086, the Program for Liaoning Excellent Talents in University under Grant LJQ2013040, the Natural Science Foundation of Liaoning Province under Grant 2014020106.

Fushun, China, September 2013

Shenyang, China

Canterbury, UK

Guoliang Wang Qingling Zhang Xinggang Yan 


\section{Contents}

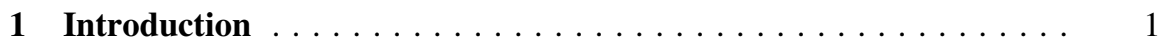

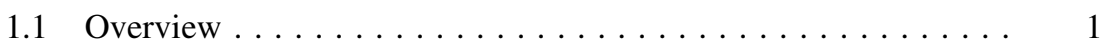

1.2 Some Examples. . . . . . . . . . . . . . . . . 3

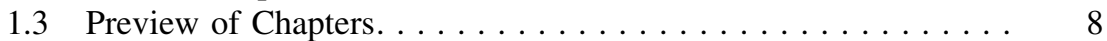

References ......................... 10

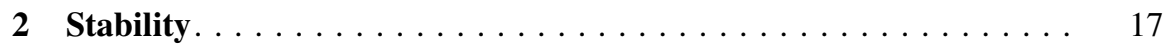

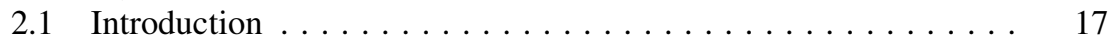

2.2 Stability with General TRMs $\ldots \ldots \ldots \ldots \ldots \ldots \ldots \ldots . \ldots \ldots$

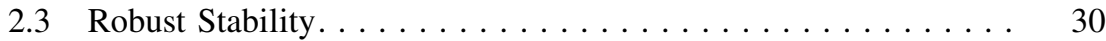

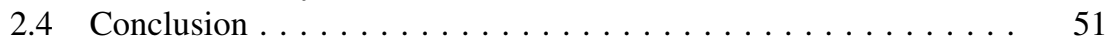

References ........................ 51

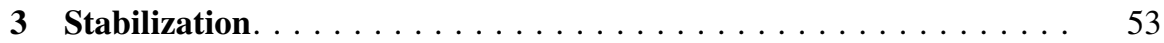

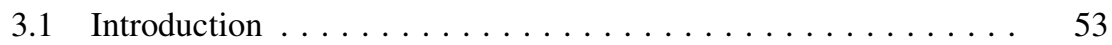

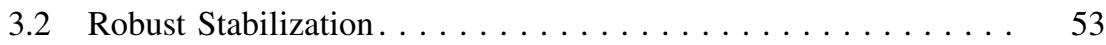

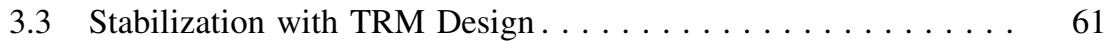

3.4 Stabilization by Noise Control $\ldots \ldots \ldots \ldots \ldots \ldots \ldots .65$

3.5 Stabilization by PD Control $\ldots \ldots \ldots \ldots \ldots \ldots \ldots \ldots . \ldots$

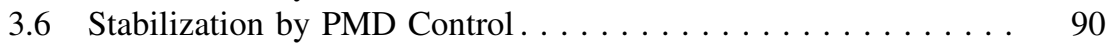

3.7 Conclusion . . . . . . . . . . . . . . . . . . . . . . . . 107

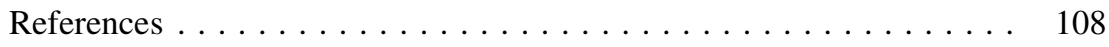

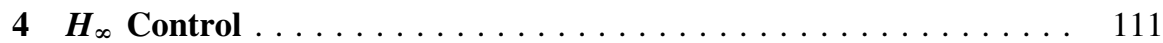

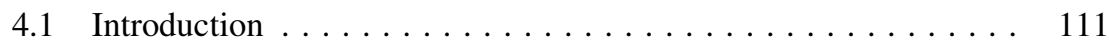

4.2 Mode-Independent $H_{\infty}$ Control with TRM Design. . . . . . . 112

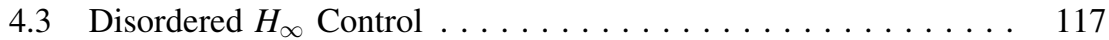

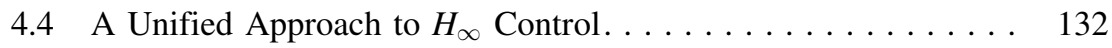

4.5 Improved Mode-Independent $H_{\infty}$ Control. . . . . . . . . . . 146

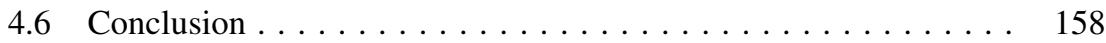

References . . . . . . . . . . . . . . . . . . . . . 159 


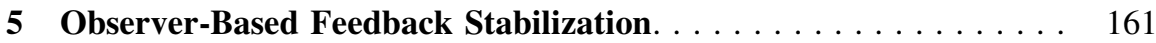

$5.1 \quad$ Introduction $\ldots \ldots \ldots \ldots \ldots \ldots \ldots \ldots \ldots \ldots \ldots \ldots \ldots$

5.2 Generally Observer-Based Controller Design . . . . . . . . . 161

5.3 Conclusion . . . . . . . . . . . . . . . . . . . . . 177

References ........................... 178

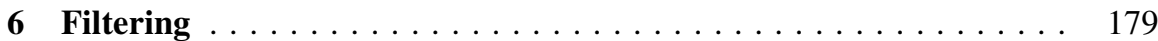

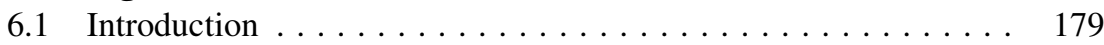

6.2 Robust $H_{\infty}$ Filtering $\ldots \ldots \ldots \ldots \ldots \ldots \ldots \ldots \ldots \ldots \ldots$

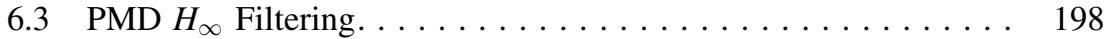

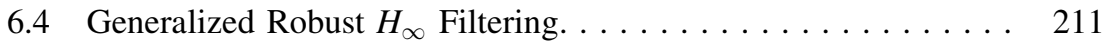

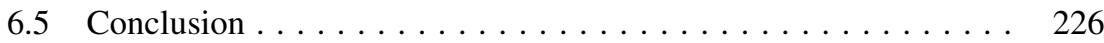

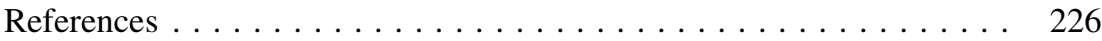

$7 \quad$ Adaptive Control . . . . . . . . . . . . . . . . . . . . . . . 229

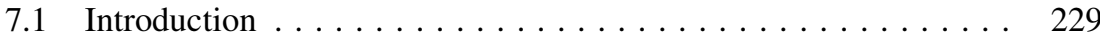

7.2 Uncertain Switching Case. . . . . . . . . . . . . . . . . 229

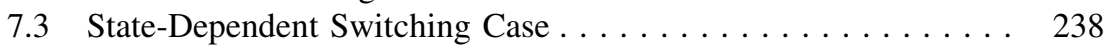

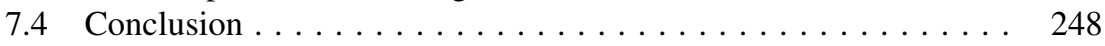

References .............................. 249

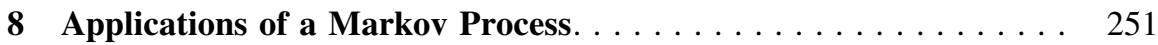

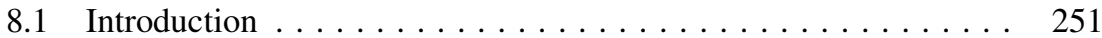

8.2 Application on Norm Bounded Uncertain Singular Systems . . . . 251

8.3 Applications on Time-delayed Singular Systems . . . . . . . . . 265

8.4 Conclusion . . . . . . . . . . . . . . . . . . . . . . . . 279

References ........................ 281

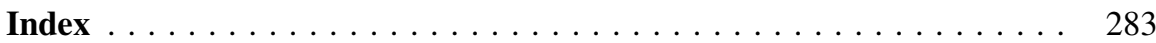




\section{Acronyms}

BRL Bounded real lemma

CCL Cone complementarity linearization

DC Direct current

MD Mode-dependent

MDC Mode-dependent controller

MI Mode-independent

MIC Mode-independent controller

MJS Markovian jump system

MJSPS Markovian jump singularly perturbed system

NOM New operation mode

SLPM Sequential linear programming matrix

SMJS Singular markovian jump system

LMI Linear matrix inequality

TRM Transition rate matrix

ODEs Ordinary differential equations

OM Operation mode

OOM Original operation mode

PD Proportional-derivative

PDSFC Proportional-derivative state feedback controller

PMD Partially mode-dependent

QNQSS Quadratically normal and quadratically stochastically stable

SSMJS Stochastic singular Markovian jump systems 